\title{
$\mathrm{Cu}-\mathrm{Sn}$ 계 솔더와 기판 사이의 $\mathrm{Ni}$ 층의 두께와 열처리 시간에 따른 금속간화합물의 기계적 특성
}

\author{
김이슬 ${ }^{1} \cdot$ 권지혜 ${ }^{1} \cdot$ 유다영 $^{2} \cdot$ 박성규 $^{2} \cdot$ 이다정 $^{2} \cdot$ 이동윤 $^{1,2,3, *}$ \\ ${ }^{1}$ 부산대학교 차세대기판학과 \\ ${ }^{2}$ 부산대학교 나노융합기술학과 \\ ${ }^{3}$ 부산대학교 나노에너지공학과
}

\section{Influence of Nickel Thickness and Annealing Time on the Mechanical Properties of Intermetallic Compounds Formed between Cu-Sn Solder and Substrate}

\author{
Yiseul Kim ${ }^{1}$, Jeehye Kwon ${ }^{1}$, Dayoung Yoo ${ }^{2}$, Sungkyu Park ${ }^{2}$, Dajeong Lee ${ }^{2}$, and Dongyun Lee 1,2,3,* \\ ${ }^{I}$ Department of Advanced Circuit Interconnection, Pusan National University, Busan 46241, Republic of Korea \\ ${ }^{2}$ Department of Nano Fusion Technology, Pusan National University, Busan 46241, Republic of Korea \\ ${ }^{3}$ Department of Nanoenergy Engineering, Pusan National University, Busan 46241, Republic of Korea
}

\begin{abstract}
Intermetallic compounds (IMCs) developed on the interface between a solder alloy and its bonding pads are an important factor in the failure of electronic circuits. In this study, the mechanical behaviors of the IMCs formed in the $\mathrm{Cu}-\mathrm{Ni}-\mathrm{Sn}$ ternary alloy system are investigated. Presumably, $\mathrm{Ni}$ can act as a diffusion barrier to $\mathrm{Cu}$ and $\mathrm{Sn}$ to form the IMCs. Detailed analysis of the microstructure is conducted using an electron probe micro-analyzer (EPMA). The addition of Ni softened the IMCs, which is determined based on the fracture toughness increasing (from 0.71 to $1.55 \mathrm{MPa} \sqrt{\mathrm{m}}$ ) with the Ni layer thickness. However, above a critical amount of $\mathrm{Ni}$ involved in the $\mathrm{Cu}-\mathrm{Sn}$ IMCs, the softening effect is diminished, and this could result from the segregation of Ni inside the IMCs. Therefore, the optimized condition must be determined in order to obtain a positive $\mathrm{Ni}$ effect on enhancing the reliability of the electronic circuits.
\end{abstract}

(Received July 22, 2016; Accepted December 13, 2016)

Keywords: $\mathrm{Pb}$-free solder; Intermetallic compound; mechanical properties, nanoindentation

\section{1. 서 론}

최근 전자제품의 소형화 및 고성능화로, 패키지 내에 더 많 은 소자 및 단자의 실장이 요구되고 있다. 이로 인해 솔더 및 피치의 크기가 급속하게 감소하고 있으며, 그에 따라 패키지 내의 전류밀도가 급격히 상승하여 기판과 다이를 이어주는 솔 더에 전류밀도가 집중되는 현상이 발생하게 된다. 이는 솔더 와 기판 사이에 전자이동(electromigration)이나 Joule 열에 의 한 확산 등으로 인해 솔더와 기판 사이에 금속간화합물 (Intermetallic Compound, IMC)과 같은 2차상을 형성한다. $\mathrm{IMC}$ 와 같은 2차상은 회로의 전기저항을 급격히 올리는 요인 이 되며 이는 단선과 같은 회로의 중대한 결함으로 작용할 수

* Corresponding Author: Dongyun Lee

[Tel: +82+51-510-6120, E-mail: dlee@pusan.ac.kr]

Copyright (c) The Korean Institute of Metals and Materials
있다. 또한, 솔더와 기판 사이에 형성될 수 있는 IMC는 취성이 강해 외부 충격에 의한 회로 단선에도 큰 영향을 미칠 수 있다 [1-3]. 따라서 높은 전류 밀도에 의한 패키지내의 온도 변화와 이에 따른 IMC의 성장거동 및 IMC가 패키지에 미치는 영향 에 대한 체계적인 연구가 필요하며, 이러한 연구는 향후 패키 지의 신뢰성 예측에도 도움을 줄 수 있을 것으로 생각된다.

솔더를 실장하기 전 표면처리 공정에서 $\mathrm{Ni}$ 이 포함되어 있 는 ENIG (Electroless Nickel Immersion Gold)의 경우 Ni이 포함되어 있지 않은 OSP(Organic Solderability Preservative) 나 주석 침지 표면처리에 비해 IMC가 얇게 형성된다 [4]. 이 는 $\mathrm{Ni}$ 이 $\mathrm{Cu}$ 의 내부 확산을 막는 역할 뿐만 아니라 $\mathrm{Sn}$ 이 $\mathrm{Cu}$ 안 으로 확산되는 것을 막기 때문으로 알려져 있다 $[4,5] . \mathrm{Sn}$ 과 $\mathrm{Cu}$ 로 구성된 솔더에서는 $\mathrm{Cu}_{3} \mathrm{Sn}, \mathrm{Cu}_{6} \mathrm{Sn}_{5}$ 등의 $\mathrm{IMC}$ 가 형성된 다. 해당 $\mathrm{IMC}$ 에 $\mathrm{Ni}$ 이 포함되면, $\mathrm{Cu}$ 는 $\mathrm{Ni}$ 과 원자의 크기 차이 
Table 1. Electroplating bath constituents for the electrodeposition of Nickel.

\begin{tabular}{c|c}
\hline Chemicals/Parameters & Conditions \\
\hline $\mathrm{NiSO}_{4} \cdot 6 \mathrm{H}_{2} \mathrm{O}$ & $240 \mathrm{~g} / \mathrm{L}(0.91 \mathrm{~mol} / \mathrm{L})$ \\
\hline $\mathrm{NiCl}_{2} \cdot 6 \mathrm{H}_{2} \mathrm{O}$ & $45 \mathrm{~g} / \mathrm{L}(0.19 \mathrm{~mol} / \mathrm{L})$ \\
\hline $\mathrm{H}_{3} \mathrm{BO}_{3}$ & $30 \mathrm{~g} / \mathrm{L}(0.49 \mathrm{~mol} / \mathrm{L})$ \\
\hline Temp. & $333 \mathrm{~K}$ \\
\hline Current density & $40 \sim 50 \mathrm{~mA} / \mathrm{cm}^{2}$ \\
\hline Time & $50 \mathrm{~s}, 120 \mathrm{~s}, 240 \mathrm{~s}$ \\
\hline
\end{tabular}

(a)

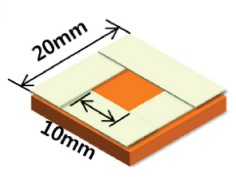

(b)

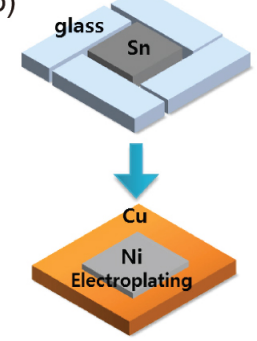

(c)

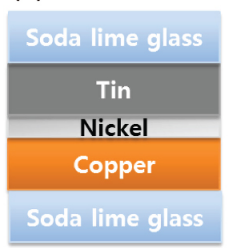

Fig. 1. Assembly of diffusion couple (a) preparation of $\mathrm{Cu}$ specimen, (b) Cu-Ni-Sn assembly, (c) annealing assembly.

가 $2 \%$ 정도로 아주 작으며, 결정구조도 $\mathrm{FCC}$ 로 같기 때문에, 격자의 변형 없이 $\mathrm{Ni}$ 이 $\mathrm{Cu}$ 와 치환되어 $\mathrm{Ni}-\mathrm{Cu}-\mathrm{Sn}$ 의 $\mathrm{IMC}$ 층을 형성한다 [6]. Ni이 포함되어있는 솔더에서는 (IMC층의 두 께가 상대적으로 얇으며 $\left(\mathrm{Cu}_{1-x} \mathrm{Ni}_{\mathrm{x}}\right)_{6} \mathrm{Sn}_{5}$ 층은 보다 두껍게 형 성된다. 이는 $\mathrm{Ni}$ 이 포함되어 있으면 ( 의 활성화 에너지는 매 우 높은 수치로 증가하고, $\left(\mathrm{Cu}_{1-\mathrm{x}} \mathrm{Ni}_{\mathrm{x}}\right)_{6} \mathrm{Sn}_{5}$ 층은 상대적으로 적 게 증가하여, $\mathrm{Ni}$ 이 포함된 $\left(\mathrm{Cu}_{1-\mathrm{x}} \mathrm{Ni}_{\mathrm{x}}\right)_{6} \mathrm{Sn}_{5}$ 층의 두께가 빠르게 증가하는 것으로 알려져 있다. $\mathrm{Ni}$ 이 포함된 IMC가 형성될 때 $\left(\mathrm{Cu}_{1-\mathrm{x}} \mathrm{N}_{\mathrm{ix}}\right)_{3} \mathrm{Sn}$ 에 비해 $\left(\mathrm{Cu}_{1-\mathrm{x}} \mathrm{Ni}_{\mathrm{x}}\right)_{6} \mathrm{Sn}_{5}$ 의 생성이 많아지지만, 결 국 두 $\mathrm{IMC}$ 상 모두 활성화 에너지가 증가하여 IMC생성이 어 려워지는 것으로 알려져 있다 [5].

따라서 본 연구에서는 $\mathrm{Cu}-\mathrm{Sn}$ 솔더에 형성되는 $\mathrm{IMC}$ 의 성 장 및 기계적 특성에 미치는 $\mathrm{Ni}$ 의 영향에 대해 알고자 하였 다. 이를 위하여 $\mathrm{Ni}$ 을 이용하여 $\mathrm{IMC}$ 를 형성시킨 후, 나노압 입시험을 통해 솔더와 기판의 계면에 생성되는 $\mathrm{Cu} / \mathrm{Ni} / \mathrm{Sn}$ $\mathrm{IMC}$ 의 기계적 특성을 파악하고, $\mathrm{Ni}$ 함량 및 열처리 시간의 변화에 따른 $\mathrm{IMC}$ 의 성장거동과 $\mathrm{Ni}$ 의 확산거동을 관찰하였 다. 또한 나노압입시험을 통해 $\mathrm{Ni}$ 이 없는 2 원계 $\mathrm{IMC}$ 와 $\mathrm{Cu} / \mathrm{Ni} / \mathrm{Sn} \mathrm{IMC}$ 의 파괴인성에 대해 비교 분석하였다.

\section{2. 실험방법}

$\mathrm{IMC}$ 의 기계적 특성을 파악하기 위해 $\mathrm{Cu}$ 위에 전기도금 통
해 $\mathrm{Ni}$ 을 올리고, 다시 $\mathrm{Sn}$ 을 올려 열처리하였다. 열처리 후 생 성되는 IMC의 기계적 특성을 나노인덴터 (Nanoindenter, G200, Agilent)를 이용하여 측정하였다. 본 연구에서 실시한 시편의 구조를 그림 1 에 나타내었다. 그림 1 (a)와 같이 순도 $99.99 \%$, 두께 $1 \mathrm{~mm}$, 크기 $20 \mathrm{~mm} \times 20 \mathrm{~mm}$ 인 Cu 중앙에 10 $\mathrm{mm} \times 10 \mathrm{~mm}$ 로 $\mathrm{Ni}$ 를 표1과 같은 도금액을 이용하였고, 1.0 $\mathrm{V}$ 의 정전압 하에서 전류밀도를 $40-50 \mathrm{~mA} / \mathrm{cm}^{2}$ 로 유지하면 서 각각 $50 \mathrm{sec}, 120 \mathrm{sec}, 240 \mathrm{sec}$ 동안 전기도금을 하였다. 전 착된 Ni 도금 두께는 3D profiler를 이용하여 확인하였다.

$\mathrm{Ni}$ 전기도금 후 순도 $99.9985 \%$, 두께 $1 \mathrm{~mm}$, 크기 $10 \mathrm{~mm} \times$ $10 \mathrm{~mm}$ 인 $\mathrm{Sn}$ 을 올려 $325^{\circ} \mathrm{C}$ 에서 $48,72,96$ 시간 동안 열처리 하였다. 시편을 냉간 마운팅하여 연마지 \#220에서 \#4000까 지 순차적으로 기계적 연마를 실시하고, 0.3 0.05 $\mu \mathrm{m}$ 크기까 지의 알루미나 서스펜션 (Buehler)을 이용하여 미세 기계 연 마를 실시한 후 나노인텐터의 강성 연속측정법(CSM)으로 기계적 특성을 평가하였다. IMC의 탄성계수 및 경도를 알아 보기 위해 Berkovich 압자를 이용하였으며 압입 깊이는 500 $\mathrm{nm}$, 변형속도는 $0.05 \mathrm{~s}^{-1}$ 로 실시하였다. 또한, $\mathrm{IMC}$ 의 변형속 도 민감성을 알아보기 위해 압입 깊이 $500 \mathrm{~nm}$, 변형 속도 $0.01 \sim 1 \mathrm{~s}^{-1}$ 로 변화를 주어 실시하였다. 마지막으로 형성된 $\mathrm{IMC}$ 의 파괴인성을 알아보기 위해 압입 깊이를 $1500 \mathrm{~nm}$, 변 형속도는 $0.05 \mathrm{~s}^{-1}$ 로 압입 실험을 진행하였다. 미세구조 분석 은 주사전자현미경(Scanning Electron Microscopy, SEM)을 이용하였으며, SEM의 후방산란전자, BSE 모드를 이용하여 $\mathrm{IMC}$ 의 성장길이를 측정하였다. 시편의 조성을 분석하기 위 해 $\mathrm{SEM}$ 에 장착된 에너지 분산형 측정기(Energy Dispersive Spectroscopy, EDS)를 사용하였으며, 보다 더 정확한 정량 분 석을 위하여 전자탐침 마이크로 분석기(Electron Probe Micro-analyzer, EPMA)를 이용하였다. IMC의 성장 길이는 $\mathrm{Cu}_{3} \mathrm{Sn}$ 계의 경우 표면에서 연속적으로 형성된 부분까지의 두 께로 하였고, $\mathrm{Cu}_{6} \mathrm{Sn}_{5}$ 계의 경우 표면에서 내부에 형성된 부분 까지를 성장 길이로 하여 측정하였다.

\section{3. 결과 및 고찰}

\section{1. 미세구조}

열에 의해 확산된 $\mathrm{Sn}$ 과 $\mathrm{Cu}$ 는 서로 반응하여 $\mathrm{Sn} / \mathrm{Ni} / \mathrm{Cu}$ 계면 에 활성화 에너지가 $\mathrm{Cu}_{3} \mathrm{Sn}$ 에 비해 상대적으로 낮은 $\mathrm{Cu}_{6} \mathrm{Sn}_{5}$ 상의 $\mathrm{IMC}$ 가 먼저 형성된다 [7]. 이후 식1에 따라 $\mathrm{Cu}_{6} \mathrm{Sn}_{5}$ 은 3 몰의 $\mathrm{Sn}$ 원자와 2 몰의 $\mathrm{Cu}_{3} \mathrm{Sn} \mathrm{IMC}$ 로 분해된다. 방출된 $\mathrm{Sn}$ 원 자는 다시 주변의 $\mathrm{Cu}$ 원자와 반응하여 새로운 $\mathrm{Cu}_{3} \mathrm{Sn}$ 상을 만 
Table 2. EPMA result of $\left(\mathrm{Cu}_{1-\mathrm{x}} \mathrm{Ni}_{\mathrm{x}}\right)_{3} \mathrm{Sn}$ and $\left(\mathrm{Cu}_{1-\mathrm{x}} \mathrm{Ni}_{\mathrm{x}}\right)_{6} \mathrm{Sn}_{5}$ for $96 \mathrm{~h}$ annealing (at \%).

\begin{tabular}{c|c|c|c|c}
\hline Ni Thickness & Specimen & $\mathrm{Ni}$ & $\mathrm{Cu}$ & $\mathrm{Sn}$ \\
\hline \multirow{2}{*}{$1 \mu \mathrm{m}$} & $\left(\mathrm{Cu}_{1-\mathrm{x}} \mathrm{Ni}_{\mathrm{x}}\right)_{3} \mathrm{Sn}$ & 1.30 & 72.4 & 26.3 \\
\cline { 2 - 5 } & $\left(\mathrm{Cu}_{1-\mathrm{x}} \mathrm{Ni}_{\mathrm{x}}\right)_{6} \mathrm{Sn}_{5}$ & 0.30 & 53.8 & 46.0 \\
\hline \multirow{2}{*}{$2 \mu \mathrm{m}$} & $\left(\mathrm{Cu}_{1-\mathrm{x}} \mathrm{Ni}_{\mathrm{x}}\right)_{3} \mathrm{Sn}$ & 1.64 & 72.4 & 25.9 \\
\cline { 2 - 5 } & $\left(\mathrm{Cu}_{1-\mathrm{x}} \mathrm{Ni}_{\mathrm{x}}\right)_{6} \mathrm{Sn}_{5}$ & 2.38 & 51.1 & 46.6 \\
\hline \multirow{2}{*}{$4 \mu \mathrm{m}$} & $\left(\mathrm{Cu}_{1-\mathrm{x}} \mathrm{Ni}_{\mathrm{x}}\right)_{3} \mathrm{Sn}$ & 1.69 & 72.3 & 26.0 \\
\cline { 2 - 5 } & $\left(\mathrm{Cu}_{1-\mathrm{x}} \mathrm{Ni}_{\mathrm{x}}\right)_{6} \mathrm{Sn}_{5}$ & 3.46 & 50.2 & 46.4 \\
\hline
\end{tabular}
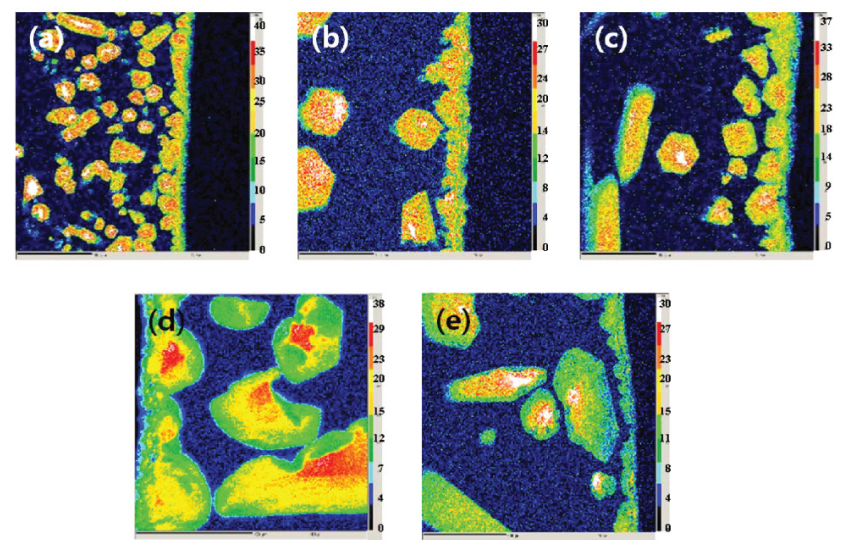

Fig. 2. EPMA mapping results of nickel thickness $4 \mu \mathrm{m}$ at $325{ }^{\circ} \mathrm{C}$ for Annealing time (red indicates Ni): (a) $12 \mathrm{~h}$; (b) $24 \mathrm{~h}$; (c) $48 \mathrm{~h}$; (d) $72 \mathrm{~h}$; (e) $96 \mathrm{~h}$.

들게 되고, 그에 따라 계면에서 먼저 형성되었던 $\mathrm{Cu}_{6} \mathrm{Sn}_{5}$ 상은 점차 분해되어 계면에는 $\mathrm{Cu}_{3} \mathrm{Sn}$ 상이 남게 되고, 시간이 지날 수록 모재의 내부로 확산된 원자들은 편석을 이루며 $\mathrm{Cu}_{6} \mathrm{Sn}_{5}$ $\mathrm{IMC}$ 를 형성하게 된다 $[5,8]$.

$$
\mathrm{Cu}_{6} \mathrm{Sn}_{5} \rightarrow 2 \mathrm{Cu}_{3} \mathrm{Sn}+3 \mathrm{Sn}
$$

$$
3 \mathrm{Sn}+9 \mathrm{Cu} \rightarrow 3 \mathrm{Cu}_{3} \mathrm{Sn}
$$

형성된 $\mathrm{Cu}_{6} \mathrm{Sn}_{5}$ 와 $\mathrm{Cu}_{3} \mathrm{Sn}$ 상은 원자 크기가 $2 \%$ 차이로 거의 유사하고, 격자구조가 같은 주변의 $\mathrm{Ni}$ 원자와 반응하여 $\left(\mathrm{Cu}_{1-\mathrm{x}} \mathrm{Ni}_{\mathrm{x}}\right)_{3} \mathrm{Sn}$ 과 $\left(\mathrm{Cu}_{1-\mathrm{x}} \mathrm{Ni}_{\mathrm{x}}\right)_{6} \mathrm{Sn}_{5}$ 상으로 변환되는 것으로 생각 된다(표2). $\mathrm{Ni}$ 의 열확산 및 $\mathrm{IMC}$ 형성을 관찰하기 위하여 $\mathrm{Ni}$ 을 전기도금을 이용하여 $1 \mu \mathrm{m}, 2 \mu \mathrm{m}, 4 \mu \mathrm{m}$ 의 두께로 코팅한 후에 $325{ }^{\circ} \mathrm{C}$ 에서 $48,72,96$ 시간 동안 열처리하였다. $\mathrm{EDS}$ 와 $\mathrm{EPMA}$ 를 이용하여 정성/정량 분석을 실시하였고, 형성된 $\mathrm{IMC}$ 의 분포 및 화학적 조성을 가장 알기 쉬운 $\mathrm{Ni} 4 \mu \mathrm{m}$ 두께, 96시간동안 열처리한 시편의 결과를 표 2와 그림 2에 나타내 었다. 표 2에서 보는 바와 같이 $\mathrm{Cu}_{3} \mathrm{Sn}$ 상과 $\mathrm{Cu}_{6} \mathrm{Sn}_{5}$ 상의 IMC
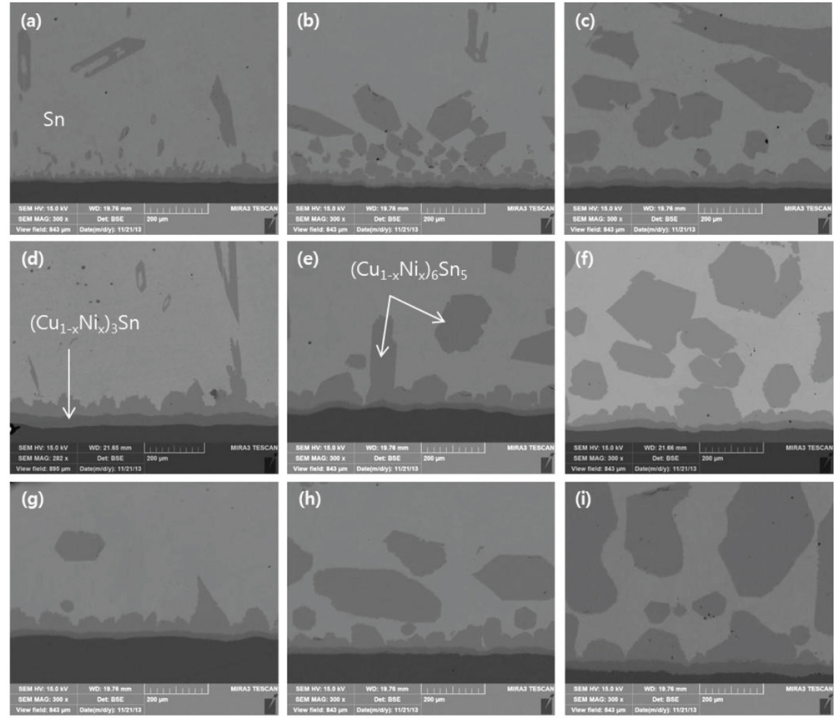

Fig. 3. BSE images (a) 48 h, $1 \mu \mathrm{m}$ (b) 48 h, $2 \mu \mathrm{m}$ (c) 48 h, $4 \mu \mathrm{m}$ (d) $72 \mathrm{~h}, 1 \mu \mathrm{m}$ (e) $72 \mathrm{~h}, 2 \mu \mathrm{m}$ (f) $72 \mathrm{~h}, 4 \mu \mathrm{m}$ (g) $96 \mathrm{~h}, 1 \mu \mathrm{m}$ (h) 96 h, $2 \mu \mathrm{m}$ (i) $96 \mathrm{~h}, 4 \mu \mathrm{m}$.

에 일부의 $\mathrm{Cu}$ 와 $\mathrm{Ni}$ 이 치환된 형태의 화학조성을 이루고 있음 을 확인할 수 있다. 그림 2에서는 $\mathrm{Ni}$ 의 분포를 (붉은색) 보다 더 정확하게 확인할 수 있는데, $\mathrm{Cu}$ 와 $\mathrm{Sn}$ (푸른색 계통) 등은 $\mathrm{IMC}$ 층에 비교적 고르게 분포되어 있는 것에 비해 $\mathrm{Ni}$ 의 경우 는 $\mathrm{IMC}$ 층 내부에 집중적으로 분포하는 것을 관찰할 수 있다. 12 시간, 24 시간, 48 시간 열처리를 한 그림 2 (a), (b), (c)의 경 우 IMC가 전반적으로 붉은색을 띄는 것을 보아 IMC 내에 $\mathrm{Ni}$ 가 비교적 고르게 분포되어 있는 것을 알 수 있다. 그러나 열 처리 시간이 72 시간 시편인 그림 $2(\mathrm{~d})$ 에서 IMC 내부에는 붉 은색을 띄며 가장자리는 초록색을 띄는 것을 보아 $\mathrm{Ni}$ 가 중심 부로 집중되기 시작했다. 그림 2 (e)의 96시간 열처리한 시편 의 경우 IMC 중심부 쪽으로 (흰색) 더욱 집중되는 것을 확인 할 수 있다. 아일랜드 형태의 IMC 형성은 재료 내부를 통한 $\mathrm{Ni}$ 의 확산에 의해서 이루어질 것이므로 표면으로부터 형성 된 IMC와 직-간접적으로 연결되어 있을 것으로 생각되며 이 를 통해 $\mathrm{Ni}$ 는 계속 확산되고 있을 것으로 판단된다. 이로 인 해 열처리 시간이 짧은 경우에는 $\mathrm{Ni}$ 가 과잉 공급되지 않았지 만 열처리 시간이 길어짐에 따라 결정립계를 따라 $\mathrm{Ni}$ 가 공급 되어 아일랜드 형태의 $\mathrm{IMC}$ 를 형성-성장해 나감으로써 $\mathrm{IMC}$ 내부에 $\mathrm{Ni}$ 가 집중되는 것처럼 관찰되는 것으로 생각된다. 그 러나 열처리 시간이 매우 길어지게 되면 결정립계를 따라 과 잉 공급된 $\mathrm{Ni}$ 가 주변으로 확산되면서 $\mathrm{Ni}$ 의 편석이 점차 사라 지는 것으로 판단된다.

$\mathrm{IMC}$ 가 계면에 생성된 이후 시편 내부로 열처리 시간에 따 
라 성장해가는 속도 (성장속도, $\mathrm{K}$ ) 및 성장속도 변화율을 이 용하여 $\left(\mathrm{Cu}_{1-\mathrm{x}} \mathrm{Ni}_{\mathrm{x}}\right)_{3} \mathrm{Sn},\left(\mathrm{Cu}_{1-\mathrm{x}} \mathrm{Ni}_{\mathrm{x}}\right)_{6} \mathrm{Sn}_{5} \mathrm{IMC}$ 의 성장거동 및 경 향을 분석할 수 있다. SEM 미세 조직 사진을 (그림 3) 이용하 여 각각 시편의 IMC 길이를 측정하고, 식 (3)을 이용하여 $\mathrm{IMC}$ 의 성장속도를 계산하여 표 3 과 같이 정리하였다.

$$
X^{2}=K t
$$

여기서 $X(\mathrm{~mm})$ 는 IMC 두께, $t$ 는 열처리 시간 $(\mathrm{sec}), K$ $\left(\mathrm{cm}^{2} / \mathrm{s}\right)$ 는 성장속도이다 [10].

$\mathrm{Ni}$ 두께가 동일할 경우, 열처리 시간의 변화에 따른 IMC 길이 및 성장속도 변화를 살펴보기 위하여, 그림 3 (a), (d), $(\mathrm{g})$ 를 비교하였다. 그림 3 에서 알 수 있듯이 열처리 시간이 길 어짐에 따라 $\mathrm{IMC}$ 의 길이가 증가하였다. $\mathrm{Ni}$ 두께가 $1 \mu \mathrm{m}$ 인 경우, $\left(\mathrm{Cu}_{1-x} \mathrm{Ni}_{\mathrm{x}}\right)_{3} \mathrm{Sn}$ 상은 열처리 시간이 $48,72,96$ 시간으로 증가함에 따라 각각 $3.756,9.872,38.845 \mu \mathrm{m}$ 로 증가하였다. 또한, $\left(\mathrm{Cu}_{1-\mathrm{x}} \mathrm{Ni}_{\mathrm{x}}\right)_{6} \mathrm{Sn}_{5}$ 상은 열처리 시간에 따라 $14.384 \mu \mathrm{m}(48$ 시간 열처리)에서 $165.639 \mu \mathrm{m}$ (96시간 열처리)로 증가하였 다. $\mathrm{Ni}$ 의 두께가 $2 \mu \mathrm{m}$ 와 $4 \mu \mathrm{m}$ 인 시편에서도 같은 경향성을 확인하였다. $\left(\mathrm{Cu}_{1-\mathrm{x}} \mathrm{Ni}_{\mathrm{x}}\right)_{3} \mathrm{Sn}$ 상의 경우 48 시간에서 72 시간으로 열처리 시간 증가 시, $1,2,4 \mu \mathrm{m}$ 평균적으로 $\mathrm{IMC}$ 길이가 3.129 배 성장하였고, 72 시간에서 96 시간으로 증가 시, 3.175 배 증 가하였다. 반면 $\left(\mathrm{Cu}_{1-x} \mathrm{Ni}_{\mathrm{x}}\right)_{6} \mathrm{Sn}_{5}$ 상의 경우는 48 시간에서 72 시 간으로 증가 시 $1,2,4 \mu \mathrm{m}$ 평균 8.378 배, 72 시간에서 96 시간으 로 증가 시, 평균 1.304 배로 앞선 $\left(\mathrm{Cu}_{1-\mathrm{x}} \mathrm{Ni}_{\mathrm{x}}\right)_{3} \mathrm{Sn}$ 상은 상에 비교 해 48시간에서 72 시간 증가 시에 훨씬 큰 길이 성장이 나타 남을 확인하였다. 그리고, 72 시간에서 96 시간 사이에선 급격 히 길이 성장이 저하되는 것을 확인할 수 있다. 이는 두 IMC 상의 활성화 에너지 차이에 의한 현상으로 48-72시간 사이에 서는 낮은 활성화 에너지를 가지는 $\left(\mathrm{Cu}_{1-\mathrm{x}} \mathrm{Ni}_{\mathrm{x}}\right)_{6} \mathrm{Sn}_{5}$ 상이 우선 급격하게 생성되지만 72-96시간 사이에서는 반응할 수 있는 $\mathrm{Sn}$ 이 부족하여 점차 상의 생성 및 성장 속도가 느려지는 것 으로 보인다. 이미 생성된 $\mathrm{Cu}$ 기반 화합물 $\left(\mathrm{Cu}_{3} \mathrm{Sn}_{\text {and }} \mathrm{Cu}_{6} \mathrm{Sn}_{5}\right)$ 들 은 $\mathrm{Sn} \operatorname{sink}$ 로 작용하여 주변에 있는 $\mathrm{Sn}$ 과 반응하거나, 계면에 생성된 $\mathrm{Cu}$ 기반 화합물들이 $\mathrm{Sn}$ 의 확산을 방해하므로[9], 열 처리 시간이 증가할수록 반응할 $\mathrm{Sn}$ 이 부족해지는 것으로 생 각된다. 반면 높은 활성화 에너지를 가지는 $\left(\mathrm{Cu}_{1-\mathrm{x}} \mathrm{Ni}_{\mathrm{x}}\right)_{3} \mathrm{Sn}$ 상 은 이미 생성된 $\left(\mathrm{Cu}_{1-\mathrm{x}} \mathrm{Ni}_{\mathrm{x}}\right)_{6} \mathrm{Sn}_{5}$ 상의 분해로 인하여 만들어지 므로, 시간의 증가에 따른 $\mathrm{IMC}$ 길이성장 변화는 큰 차이가 없는 것으로 보인다. 이와 같은 경향은 성장속도 증가율을 통 해서도 확인 할 수 있다. $\left(\mathrm{Cu}_{1-\mathrm{x}} \mathrm{Ni}_{\mathrm{x}}\right)_{3} \mathrm{Sn}$ 상은 1,2 , 그리고 $4 \mu \mathrm{m}$
Table 3. Length of IMCs and growth rate.

\begin{tabular}{|c|c|c|c|c|c|}
\hline $\begin{array}{l}\text { Aging } \\
\text { time }\end{array}$ & $\begin{array}{c}\mathrm{Ni} \\
\text { thickness }\end{array}$ & specimen & $\begin{array}{c}\text { IMC } \\
\text { length } \\
(\mu \mathrm{m})\end{array}$ & $\begin{array}{c}\text { growth rate } \\
\left(\mathrm{cm}^{2} / \mathrm{s}\right)\end{array}$ & Ref. \\
\hline \multirow{2}{*}{$48 \mathrm{~h}$} & & $\mathrm{Cu}_{3} \mathrm{Sn}$ & 39.1 & $8.8 \times 10^{-11}$ & \multirow{2}{*}[15]{} \\
\hline & & $\mathrm{Cu}_{6} \mathrm{Sn}_{5}$ & 152 & $1.3 \times 10^{-7}$ & \\
\hline \multirow{6}{*}{$48 \mathrm{~h}$} & \multirow{2}{*}{$1 \mu \mathrm{m}$} & $\left(\mathrm{Cu}_{1-\mathrm{x}} \mathrm{Ni}_{\mathrm{x}}\right)_{3} \mathrm{Sn}$ & 3.8 & $8.2 \times 10^{-13}$ & \multirow{18}{*}{$\begin{array}{l}\text { This } \\
\text { study }\end{array}$} \\
\hline & & $\left(\mathrm{Cu}_{1-\mathrm{x}} \mathrm{Ni}_{\mathrm{x}}\right)_{6} \mathrm{Sn}_{5}$ & 14.4 & $1.2 \times 10^{-11}$ & \\
\hline & \multirow{2}{*}{$2 \mu \mathrm{m}$} & $\left(\mathrm{Cu}_{1-\mathrm{x}} \mathrm{Ni}_{\mathrm{x}}\right)_{3} \mathrm{Sn}$ & 3.4 & $6.6 \times 10^{-13}$ & \\
\hline & & $\left(\mathrm{Cu}_{1-\mathrm{x}} \mathrm{Ni}_{\mathrm{x}}\right)_{6} \mathrm{Sn}_{5}$ & 15.8 & $1.4 \times 10^{-11}$ & \\
\hline & \multirow{2}{*}{$4 \mu \mathrm{m}$} & $\left(\mathrm{Cu}_{1-\mathrm{x}} \mathrm{Ni}_{\mathrm{x}}\right)_{3} \mathrm{Sn}$ & 8.5 & $4.2 \times 10^{-12}$ & \\
\hline & & $\left(\mathrm{Cu}_{1-\mathrm{x}} \mathrm{Ni}_{\mathrm{x}}\right)_{6} \mathrm{Sn}_{5}$ & 24.1 & $3.4 \times 10^{-11}$ & \\
\hline \multirow{6}{*}{$72 \mathrm{~h}$} & \multirow{2}{*}{$1 \mu \mathrm{m}$} & $\left(\mathrm{Cu}_{1-\mathrm{x}} \mathrm{Ni}_{\mathrm{x}}\right)_{3} \mathrm{Sn}$ & 9.9 & $3.8 \times 10^{-12}$ & \\
\hline & & $\left(\mathrm{Cu}_{1-\mathrm{x}} \mathrm{Ni}_{\mathrm{x}}\right)_{6} \mathrm{Sn}_{5}$ & 120.6 & $5.6 \times 10^{-10}$ & \\
\hline & um & $\left(\mathrm{Cu}_{1-\mathrm{x}} \mathrm{Ni}_{\mathrm{x}}\right)_{3} \mathrm{Sn}$ & 10.5 & $4.3 \times 10^{-12}$ & \\
\hline & $2 \mu \mathrm{m}$ & $\left(\mathrm{Cu}_{1-\mathrm{x}} \mathrm{Ni}_{\mathrm{x}}\right)_{6} \mathrm{Sn}_{5}$ & 141.2 & $7.7 \times 10^{-10}$ & \\
\hline & 4 & $\left(\mathrm{Cu}_{1-\mathrm{x}} \mathrm{Ni}_{\mathrm{x}}\right)_{3} \mathrm{Sn}$ & 31 & $3.7 \times 10^{-11}$ & \\
\hline & $4 \mu \mathrm{m}$ & $\left(\mathrm{Cu}_{1-\mathrm{x}} \mathrm{Ni}_{\mathrm{x}}\right)_{6} \mathrm{Sn}_{5}$ & 189 & $1.4 \times 10^{-9}$ & \\
\hline \multirow{6}{*}{$96 \mathrm{~h}$} & \multirow{2}{*}{$1 \mu \mathrm{m}$} & $\left(\mathrm{Cu}_{1-\mathrm{x}} \mathrm{Ni}_{\mathrm{x}}\right)_{3} \mathrm{Sn}$ & 38.8 & $4.4 \times 10^{-11}$ & \\
\hline & & $\left(\mathrm{Cu}_{1-\mathrm{x}} \mathrm{Ni}_{\mathrm{x}}\right)_{6} \mathrm{Sn}_{5}$ & 165.6 & $7.9 \times 10^{-10}$ & \\
\hline & \multirow{2}{*}{$2 \mu \mathrm{m}$} & $\left(\mathrm{Cu}_{1-\mathrm{x}} \mathrm{Ni}_{\mathrm{x}}\right)_{3} \mathrm{Sn}$ & 40.7 & $4.8 \times 10^{-11}$ & \\
\hline & & $\left(\mathrm{Cu}_{1-\mathrm{x}} \mathrm{Ni}_{\mathrm{x}}\right)_{6} \mathrm{Sn}_{5}$ & 189.5 & $1.0 \times 10^{-9}$ & \\
\hline & \multirow{2}{*}{$4 \mu \mathrm{m}$} & $\left(\mathrm{Cu}_{1-\mathrm{x}} \mathrm{Ni}_{\mathrm{x}}\right)_{3} \mathrm{Sn}$ & 51.6 & $7.7 \times 10^{-11}$ & \\
\hline & & $\left(\mathrm{Cu}_{1-\mathrm{x}} \mathrm{Ni}_{\mathrm{x}}\right)_{6} \mathrm{Sn}_{5}$ & 226.5 & $1.5 \times 10^{-9}$ & \\
\hline
\end{tabular}

두께의 $\mathrm{Ni}$ 를 48 시간에서 72 시간으로 열처리 시간을 증가했 을 때, 평균 6.649 배의 성장속도증가율을 나타냈으며 72 시간 에서 96시간으로 증가 시 평균 8.307 배의 성장속도 증가를 확인하였다. 반면 $\left(\mathrm{Cu}_{1-\mathrm{x}} \mathrm{Ni}_{\mathrm{x}}\right)_{6} \mathrm{Sn}_{5}$ 상의 경우 48 시간에서 72 시 간 증가 시 46.93배의 평균 성장속도 증가를 확인하였고 72 시간에서 96 시간 증가 시 평균 1.281 배의 미미한 평균 성장 속도증가를 확인하였다. $\left(\mathrm{Cu}_{1-\mathrm{x}} \mathrm{Ni}_{\mathrm{x}}\right)_{3} \mathrm{Sn}$ 상의 경우 평균 성장속 도 증가율이 6.649배와 8.307배로 유사하였으나 $\left(\mathrm{Cu}_{1-\mathrm{x}} \mathrm{Ni}_{\mathrm{x}}\right)_{6} \mathrm{Sn}_{5}$ 상 상은 46.93 배와 1.281 배로 현격한 차이를 나타내었다.

다음으로 동일 열처리 시간에서 $\mathrm{Ni}$ 두께 변화에 따른 IMC 의 길이와 성장속도를 비교하였다. 그림 3 (a), (b), (c)를 보면 $\mathrm{Ni}$ 두께가 두꺼울수록 $\mathrm{IMC}$ 의 길이가 길어지며 성장속도가 증가한다. $\mathrm{Ni}$ 두께 $1 \mu \mathrm{m}$ 와 $2 \mu \mathrm{m}$ 는 비교적 비슷한 성장속도 를 나타내나, $\mathrm{Ni}$ 두께가 $4 \mu \mathrm{m}$ 일 때는 성장속도가 더욱 빨라 졌다. $\mathrm{Cu}-\mathrm{Ni}-\mathrm{Sn} \mathrm{IMC}$ 가 생성될 때 용융된 $\mathrm{Sn}$ 이 Ni과 먼저 반 응하여 Ni-Sn IMC를 형성하며 먼저 소진되고, $\mathrm{Ni}$ 과의 반응 에 참여하지 않는 $\mathrm{Sn}$ 은 $\mathrm{Cu}$ 와 반응하여 $\mathrm{Cu}-\mathrm{Sn} \mathrm{IMC}$ 를 형성하 는 것으로 알려져 있다 [11]. 이렇듯 $\mathrm{Ni}$ 두께가 두꺼우면 $\mathrm{Sn}$ 
Table 4. Hardness and modulus of IMCs.

\begin{tabular}{|c|c|c|c|c|c|}
\hline $\begin{array}{c}\text { Aging } \\
\text { time }\end{array}$ & \begin{tabular}{|c|}
$\mathrm{Ni}$ \\
thickness \\
\end{tabular} & specimen & \begin{tabular}{|c|}
$\begin{array}{c}\text { Hardness } \\
(\mathrm{GPa})\end{array}$ \\
\end{tabular} & $\begin{array}{c}\text { Modulus } \\
(\mathrm{GPa})\end{array}$ & Ref. \\
\hline & & $\mathrm{Cu}-\mathrm{Ni}-\mathrm{Sn}$ & 7.0 & 111.5 & {$[12]$} \\
\hline \multirow{6}{*}{$48 \mathrm{~h}$} & \multirow{2}{*}{$1 \mu \mathrm{m}$} & $\left(\mathrm{Cu}_{1-\mathrm{x}} \mathrm{Nix}\right)_{3} \mathrm{Sn}$ & $6.7 \pm 0.2$ & $134.9 \pm 2.1$ & \multirow{18}{*}{$\begin{array}{l}\text { This } \\
\text { study }\end{array}$} \\
\hline & & $\left(\mathrm{Cu}_{1-\mathrm{x}} \mathrm{Ni}_{\mathrm{x}}\right)_{6} \mathrm{Sn}_{5}$ & $7.0 \pm 0.2$ & $119.9 \pm 0.2$ & \\
\hline & \multirow{2}{*}{$2 \mu \mathrm{m}$} & $\left(\mathrm{Cu}_{1-\mathrm{x}} \mathrm{Ni}_{\mathrm{x}}\right)_{3} \mathrm{Sn}$ & $6.6 \pm 0.2$ & $120.1 \pm 2.4$ & \\
\hline & & $\left(\mathrm{Cu}_{1-\mathrm{x}} \mathrm{Ni}_{\mathrm{x}}\right)_{6} \mathrm{Sn}_{5}$ & $6.5 \pm 0.2$ & $116.5 \pm 0.7$ & \\
\hline & \multirow{2}{*}{$4 \mu \mathrm{m}$} & $\left(\mathrm{Cu}_{1-\mathrm{x}} \mathrm{Ni}_{\mathrm{x}}\right)_{3} \mathrm{Sn}$ & $4.47 \pm 0.2$ & $96.1 \pm 1.5$ & \\
\hline & & $\left(\mathrm{Cu}_{1-\mathrm{x}} \mathrm{Ni}_{\mathrm{x}}\right)_{6} \mathrm{Sn}_{5}$ & $4.6 \pm 0.2$ & $89.7 \pm 2.0$ & \\
\hline \multirow{6}{*}{$72 \mathrm{~h}$} & \multirow{2}{*}{$1 \mu \mathrm{m}$} & $\left(\mathrm{Cu}_{1-\mathrm{x}} \mathrm{Ni}_{\mathrm{x}}\right)_{3} \mathrm{Sn}$ & $6.0 \pm 0.2$ & $133.2 \pm 0.9$ & \\
\hline & & $\left(\mathrm{Cu}_{1-\mathrm{x}} \mathrm{Ni}_{\mathrm{x}}\right)_{6} \mathrm{Sn}_{5}$ & $6.6 \pm 0.3$ & $119.7 \pm 1.1$ & \\
\hline & \multirow{2}{*}{$2 \mu \mathrm{m}$} & $\left(\mathrm{Cu}_{1-\mathrm{x}} \mathrm{Ni}_{\mathrm{x}}\right)_{3} \mathrm{Sn}$ & $5.5 \pm 0.3$ & $123.2 \pm 0.6$ & \\
\hline & & $\left(\mathrm{Cu}_{1-\mathrm{x}} \mathrm{Ni}_{\mathrm{x}}\right)_{6} \mathrm{Sn}_{5}$ & $6.5 \pm 0.2$ & $114.9 \pm 3.0$ & \\
\hline & \multirow{2}{*}{$4 \mu \mathrm{m}$} & $\left(\mathrm{Cu}_{1-\mathrm{x}} \mathrm{Ni}_{\mathrm{x}}\right)_{3} \mathrm{Sn}$ & $3.9 \pm 0.2$ & $88.2 \pm 1.2$ & \\
\hline & & $\left(\mathrm{Cu}_{1-\mathrm{x}} \mathrm{Ni}_{\mathrm{x}}\right)_{6} \mathrm{Sn}_{5}$ & $3.9 \pm 0.1$ & $76.9 \pm 1.0$ & \\
\hline \multirow{6}{*}{$96 \mathrm{~h}$} & \multirow{2}{*}{$1 \mu \mathrm{m}$} & $\left(\mathrm{Cu}_{1-\mathrm{x}} \mathrm{Ni}_{\mathrm{x}}\right)_{3} \mathrm{Sn}$ & $6.4 \pm 0.6$ & $133.3 \pm 2.2$ & \\
\hline & & $\left(\mathrm{Cu}_{1-\mathrm{x}} \mathrm{Ni}_{\mathrm{x}}\right)_{6} \mathrm{Sn}_{5}$ & $6.9 \pm 0.2$ & $119.8 \pm 1.5$ & \\
\hline & $4 \mathrm{~m}$ & $\left(\mathrm{Cu}_{1-\mathrm{x}} \mathrm{Ni}_{\mathrm{x}}\right)_{3} \mathrm{Sn}$ & $6.0 \pm 0.3$ & $126.6 \pm 1.5$ & \\
\hline & $2 \mu \mathrm{m}$ & $\left(\mathrm{Cu}_{1-\mathrm{x}} \mathrm{Ni}_{\mathrm{x}}\right)_{6} \mathrm{Sn}_{5}$ & $6.5 \pm 0.4$ & $108.8 \pm 4.3$ & \\
\hline & $4 \mathrm{um}$ & $\left(\mathrm{Cu}_{1-\mathrm{x}} \mathrm{Ni}_{\mathrm{x}}\right)_{3} \mathrm{Sn}$ & $5.4 \pm 0.1$ & $95.4 \pm 0.2$ & \\
\hline & $4 \mu \mathrm{m}$ & $\left(\mathrm{Cu}_{1-\mathrm{x}} \mathrm{Ni}_{\mathrm{x}}\right)_{6} \mathrm{Sn}_{5}$ & $5.6 \pm 0.2$ & $90.0 \pm 0.3$ & \\
\hline
\end{tabular}

과 반응할 $\mathrm{Ni}$ 이 충분하므로 두꺼운 $\mathrm{Ni}-\mathrm{Sn} \mathrm{IMC}$ 를 형성하고, 이후 $\mathrm{Cu}$ 와 반응하여 $\mathrm{Cu}-\mathrm{Ni}-\mathrm{Sn} \mathrm{IMC}$ 의 두께가 두꺼워지게 되 며, 성장속도도 빨라지는 것으로 판단된다. 열처리 온도와 시 간은 동일하지만 $\left(325{ }^{\circ} \mathrm{C}, 48\right.$ 시간), $\mathrm{Ni}$ 이 포함되어있지 않은 기존 문헌[15]과 비교해보면, $\mathrm{Ni}$ 이 포함된 본 실험의 IMC 길 이가 더 짧고 성장속도가 느리다. 이를 통해 $\mathrm{Ni}$ 이 확산방지막 역할을 하는 것으로 판단할 수 있다. $\mathrm{Cu}-\mathrm{Sn}-\mathrm{Ni} \mathrm{IMC}$ 의 경우 $\mathrm{Ni}$ 두께가 두꺼워짐에 따라 IMC의 두께가 두꺼워지기 때문 에 패키지의 신뢰성이 좋지 않다. 그러나 $\mathrm{Ni}$ 이 포함되어 있지 않은 $\mathrm{Cu}-\mathrm{Sn} \mathrm{IMC}$ 에 비해 $\mathrm{IMC}$ 의 길이가 짧고, 성장속도가 느 리므로, 적절한 두께의 $\mathrm{Ni}$ 도금을 이용한 표면처리는 패키지 의 신뢰성을 향상시킬 수 있을 것으로 판단된다.

\section{2. 기계적 특성}

$\mathrm{Cu}-\mathrm{Sn}-\mathrm{Ni} \mathrm{IMC}$ 의 탄성계수 및 경도, 복수돌출(multiple pop-in) 그리고 파괴인성을 측정하기 위하여, 나노압입시험 을 진행하였다. 먼저 $\mathrm{Ni}$ 의 두께와 열처리 시간에 따른 탄성계 수와 경도를 측정하여 표 4와 같이 정리하였다. Sn-2.0Ag-1.0 $\mathrm{Cu}-1.0 \mathrm{Ni}$ 솔더에 의해 생성된 IMC의 기계적 특성을 평가한 기존 문헌 [12]은 $\mathrm{Ni}$ 의 함량을 정확히 알 수 없고 나노압입시 험 시 변형 속도 $0.1 \mathrm{~s}^{-1}$, 압입깊이 200 250 nm로 본 실험의 조건과 다르기 때문에 정확한 비교가 어렵지만, 결과 값이 $\mathrm{Cu}-\mathrm{Ni}-\mathrm{Sn}$ 의 경우 경도는 $7.01 \mathrm{GPa}$, 탄성계수는 $111.5 \mathrm{GPa}$ 로
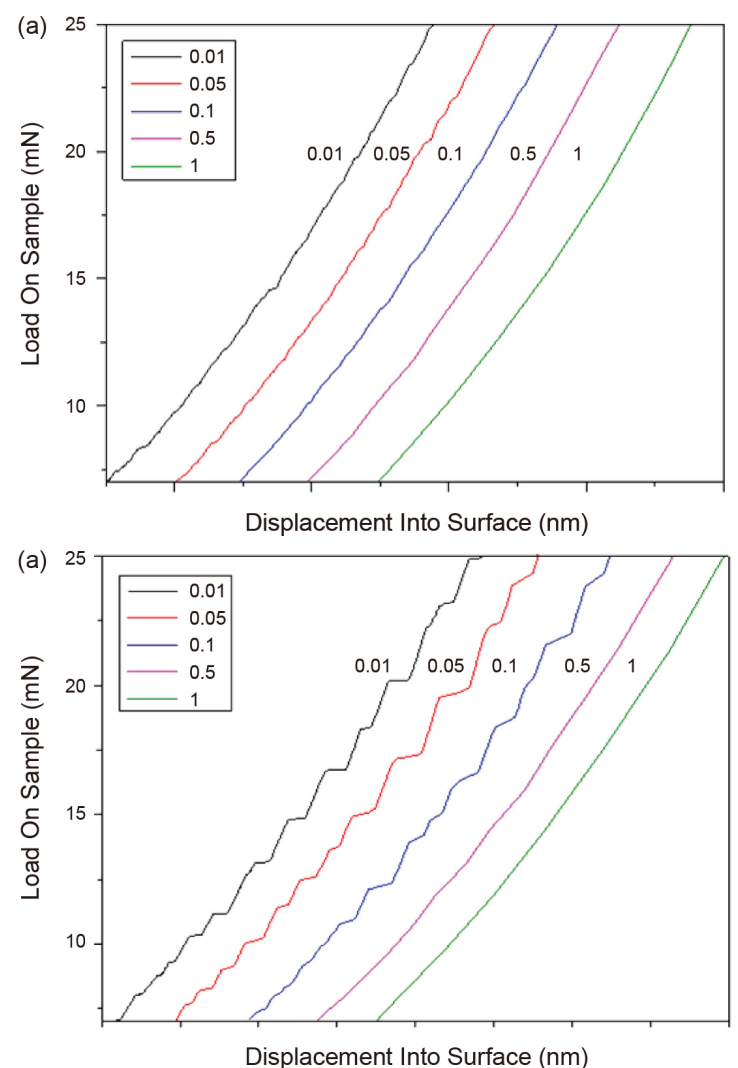

Fig. 4. Load-Displacement curves of $\mathrm{Ni} 4 \mathrm{~mm}$ sample annealed at $325 \mathrm{C}$ for $96 \mathrm{~h}$ : (a) $\left(\mathrm{Cu}_{1-\mathrm{x}} \mathrm{Ni}_{\mathrm{x}}\right)_{3} \mathrm{Sn}$; and (b) $\left(\mathrm{Cu}_{1-\mathrm{x}} \mathrm{Ni}_{\mathrm{x}}\right)_{6} \mathrm{Sn}_{5}$. (Note: numbers in graphs are strain rate $1 / \mathrm{s})$.

본 실험의 결과 값과 유사한 것을 알 수 있다. 본 연구의 결과 $\mathrm{Ni}$ 의 두께가 두꺼울수록 기계적 물성이 낮게 나왔으며, 열처 리 시간에 따라서는 비슷한 특성을 나타내는 것을 확인하였 다. 이러한 기계적 물성의 변화 원인을 알아보기 위해 EPMA 를 이용하였다. 정량분석결과 표 2 와 같이 $\mathrm{Ni}$ 두께가 두꺼워 짐에 따라 $\mathrm{IMC}$ 내에 $\mathrm{Ni}$ 함량이 많아지게 되고, 이로 인해 $\mathrm{IMC}$ 의 기계적 물성이 변화한 것으로 예상된다. $\mathrm{Cu}-\mathrm{Sn} \mathrm{IMC}$ 의 경우 장범위 규칙 상태를 유지하고 있지만 $\mathrm{Ni}$ 이 확산되면 서 $\mathrm{Ni}$ 에 의해 규칙 상태가 조금씩 깨어지게 될 것이다. $\mathrm{Ni}$ 의 함량이 높아지면 그만큼 $\mathrm{Cu}-\mathrm{Sn} \mathrm{IMC}$ 의 장범위 규칙상태가 많이 흐트러지므로 기계적 물성치가 떨어지는 것으로 판단 된다. $12,24,48,72,96$ 시간 동안 열처리 한 시편의 정성분석 결과를 그림 2에 나타내었으며, $\mathrm{Cu}$ 와 $\mathrm{Sn}$ 의 경우 $\mathrm{IMC}$ 층에 비 교적 고르게 분포되어 있었다. 그러나 앞서 설명한 바와 같이 $\mathrm{Ni}$ 의 경우 열처리 시간에 따라 $\mathrm{IMC}$ 내부로 편석이 일어났다. 그림 2 를 보면 $\mathrm{IMC}$ 는 아일랜드 형태와 표면에 균일한 형태 가 함께 관찰되는데 아일랜드 IMC는 입계 확산을 통해 불균 

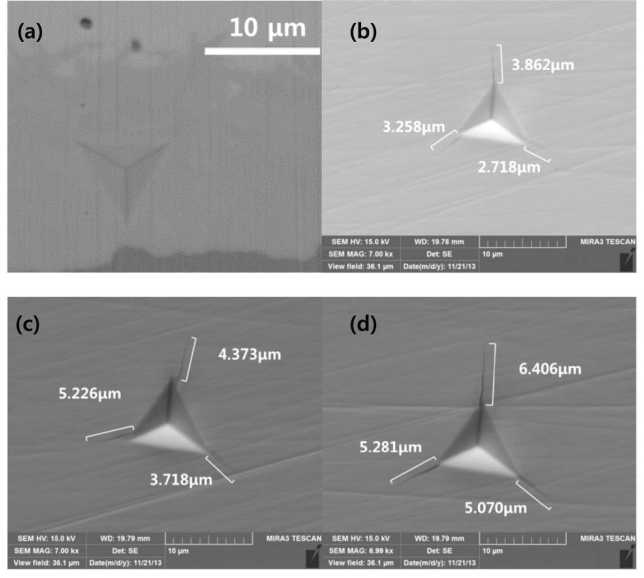

Fig. 5. SEM image of indents on (a) $\left(\mathrm{Cu}_{1-\mathrm{x}} \mathrm{Ni}_{\mathrm{x}}\right)_{3} \mathrm{Sn} \mathrm{Ni} 2 \mu \mathrm{m}$; indents on $\left(\mathrm{Cu}_{1-\mathrm{x}} \mathrm{Ni}_{\mathrm{x}}\right)_{6} \mathrm{Sn}_{5}$ (b) Ni $1 \mu \mathrm{m}$, (c) Ni $2 \mu \mathrm{m}$, (d) Ni $4 \mu \mathrm{m}$.

일하게 3차원적으로 성장한 $\mathrm{IMC}$ 를 기계적 연마를 통해 단면 을 관찰함으로써 나타나게 된 미세구조로 판단된다. 아일랜 드 형태의 IMC는 아마도 재료 내부를 통해서 표면에서 형성 된 $\mathrm{IMC}$ 와 연결되어 있으며 계속해서 $\mathrm{Ni}$ 이 확산되고 있을 것 으로 판단된다. 이로 인해 열처리 시간이 짧은 경우에는 $\mathrm{Ni}$ 이 과잉 공급되지 않았지만 열처리 시간이 길어짐에 따라 결정 립계를 따라 $\mathrm{Ni}$ 이 공급되어 아일랜드 형태의 $\mathrm{IMC}$ 를 형성-성 장해 나감으로써 $\mathrm{IMC}$ 내부에 $\mathrm{Ni}$ 이 집중되는 것처럼 관찰되 는 것으로 생각된다. 그러나 열처리 시간이 매우 길어지게 되 면 결정립계를 따라 과잉 공급된 $\mathrm{Ni}$ 이 주변으로 확산되면서 $\mathrm{Ni}$ 편석의 정도가 점차 줄어들 것으로 판단된다.

다음으로, 변형 속도 조절을 통해 복수 돌출을 관찰하였다. 본 실험에서는 변형 속도를 $0.01 \sim 1 \mathrm{~s}^{-1}$ 로 변화를 주었다. 그림 4에서 보듯이 $\mathrm{Ni}$ 이 포함되어 있는 $\left(\mathrm{Cu}_{1-\mathrm{x}} \mathrm{Ni}_{\mathrm{x}}\right)_{3} \mathrm{Sn}$ 상의 경우 복 수돌출이 나타나지 않지만, $\left(\mathrm{Cu}_{1-\mathrm{x}} \mathrm{Ni}_{\mathrm{x}}\right)_{6} \mathrm{Sn}_{5}$ 상에서는 변형 속 도가 느릴 때 복수돌출이 나타났다가 변형 속도가 빨라지면 서 사라지는 것을 확인할 수 있다. 복수돌출 현상은 슬립계가 많지 않은 취성을 띠는 물질에서 하중에 의해 다수의 전위가 생성되고 이들이 움직이는 연속적인 작용에 의해서 일어난 다고 알려져 있다. 기존 연구에서도 같은 경향의 연구 결과를 발표하였는데 [13], $\mathrm{Cu}_{6} \mathrm{Sn}_{5}$ 에서 발생하는 복수돌출의 경우 전위에 의한 소성변형과 밀접한 연관이 있고 변형 속도 증가 에 따라 전위의 생성 및 움직임에 많은 영향을 주어 전위들이 얽혀 있는 것을 알 수 있다. 이에 관련하여 전단응력 전위 속 도 관계식인 식 (2)를 사용하여 전위속도 경향을 분석하였다 [14].

$$
v=A \tau^{m}
$$

$v$ 는 전위속도, $A$ 는 물질상수, $m$ 은 $300 \mathrm{~K}$ 의 고순도 결정 일 때 1 이며 합금일 때는 $2 \sim 5, \tau$ 는 전단응력이다 [14]. 이를 통해 전단응력이 증가하면 전위속도가 증가함을 알 수 있다.

상용 유한요소해석프로그램인 Ansys를 사용하여 유한요 소해석법을 이용한 von-Mises 응력과 전단응력을 구한 문헌 을 통해 변형 속도가 $1 \mathrm{~s}^{-1}$ 일 때가 $0.01 \mathrm{~s}^{-1}$ 일 때보다 전단응력 이 크며 전단응력 분포 또한 변형 속도 $1 \mathrm{~s}^{-1}$ 일 때 더 높은 값 의 전단응력이 압입지점에 높은 밀도로 분포되어 있음을 알 수 있다 [15]. 변형 속도가 느릴 경우 탄성변형에서 탄소성변 형으로 다시 탄성변형으로 전환되는 과정이 반복적으로 이 루어지면서 복수 돌출이 관찰된다. 그러나 변형 속도가 빨라 지면 전단응력이 증가하게 되므로 식 (2)에 의해 전위 속도가 증가함을 알 수 있으며 동시에 소성변형이 빨리 이루어지게 되어 재료의 탄성변형과 탄소성변형이 전환되는 과정이 빨 리 일어남과 동시에 반력이 커지게 되고 이로 인해 전위영역 이 얽히게 되어 이를 인덴터가 감지를 하지 못해 복수 돌출이 사라진다고 서술하고 있다 [15]. $\left(\mathrm{Cu}_{1-\mathrm{x}} \mathrm{Ni}_{\mathrm{x}}\right)_{6} \mathrm{Sn}_{5}$ 상은 $\mathrm{Ni}$ 가 일 부 $\mathrm{Cu}$ 와 치환이 되어 생성되게 되는데 이때 치환이 되더라도 $\mathrm{Cu}_{6} \mathrm{Sn}_{5}$ 상의 기본적인 특성은 그대로 유지하기 때문에 $\left(\mathrm{Cu}_{1-\mathrm{x}} \mathrm{Ni}_{\mathrm{x}}\right)_{6} \mathrm{Sn}_{5}$ 상의 경우 $\mathrm{Cu}_{6} \mathrm{Sn}_{5}$ 상과 같이 복수 돌출이 나타나 는 것으로 판단된다. 그러나, 기존의 연구[11]와 비교했을 때 pop-in으로 인해 증가하는 변형량이 더 큰 것을 알 수 있는데, 이는 $\mathrm{Ni}$ 의 치환으로 인해 탄성계수와 경도값이 감소하는, 즉 연화 현상이 일어나는 것과 관련이 있다고 판단된다.

그림 5는 본 연구에서 형성된 $\mathrm{IMC}$ 의 파괴인성을 측정한 결과이다. 파괴인성을 측정하기 위해 범용으로 사용되는 Berkovich 압자를 사용하였고, 압입 깊이는 $1500 \mathrm{~nm}$, 변형 속도는 0.05 로 시험하였다. 각 상의 $\mathrm{Ni}$ 두께에 따른 파괴인성 경향을 분석하기 위해, 압입파괴인성 평가식인 식(3)을 이용 하였다.

$$
K_{c}=\alpha\left(\frac{E}{H}\right)^{1 / 2} \times\left(\frac{P_{\max }}{c^{3 / 2}}\right)
$$

$\alpha$ 는 압자 형상에 따른 상수로 Berkovich의 경우 $0.016, E$ $(\mathrm{GPa})$ 는 탄성계수, $H(\mathrm{GPa})$ 는 경도, $P(\mathrm{mN})$ 는 압입 하중, $C$ 는 균열의 길이 $(\mu \mathrm{m})$ 이다.

$\left(\mathrm{Cu}_{1-\mathrm{x}} \mathrm{Ni}_{\mathrm{x}}\right)_{3} \mathrm{Sn}$ 상에서는 모든 $\mathrm{Ni}$ 두께에서 균열이 발견되지 않았고 그림 5 (a)는 대표적인 결과를 보여준다. 이에 반해, 
Table 5. Length of propagation length and Fracture toughness with $1500 \mathrm{~nm}$ indentation depth.

\begin{tabular}{c|c|c|c|c}
\hline Specimen & $\begin{array}{c}\mathrm{Ni} \\
\text { Thickness } \\
(\mu \mathrm{m})\end{array}$ & $\begin{array}{c}\text { Crack } \\
\text { length } \\
(\mu \mathrm{m})\end{array}$ & $\begin{array}{c}\text { Fracture } \\
\text { Toughness } \\
(\mathrm{MPa} \sqrt{\mathrm{m}})\end{array}$ & Ref. \\
\hline $\mathrm{Cu}_{6} \mathrm{Sn}_{5}$ & & $5.7 \pm 1.3$ & $0.7 \pm 0.2$ & {$[13]$} \\
\hline \multirow{3}{*}{$\left(\mathrm{Cu}_{1-\mathrm{x}} \mathrm{Ni}_{\mathrm{x}}\right)_{6} \mathrm{Sn}_{5}$} & 1 & $3.7 \pm 0.7$ & $1.6 \pm 0.5$ & \multirow{2}{*}{\begin{tabular}{c} 
This \\
\cline { 2 - 4 }
\end{tabular}} \\
\cline { 2 - 4 } & 2 & $4.5 \pm 0.9$ & $1.1 \pm 0.3$ & study \\
\hline
\end{tabular}

$\left(\mathrm{Cu}_{1-\mathrm{x}} \mathrm{Ni}_{\mathrm{x}}\right)_{6} \mathrm{Sn}_{5}$ 상에서는 $\mathrm{Ni}$ 두께에 관계없이 균열이 형성되었 으며, 균열길이와 파괴인성을 표5에 정리하였다. $\left(\mathrm{Cu}_{1-\mathrm{x}} \mathrm{Ni}_{\mathrm{x}}\right)_{6} \mathrm{Sn}_{5}$ 상의 경우 첨가된 $\mathrm{Ni}$ 의 함량이 증가함에 따라 균열의 길이가 길어지며 파괴인성이 작아지는 것을 알 수 있다. 이는 $\mathrm{Cu}_{6} \mathrm{Sn}_{5}$ 의 경우 K. Nogita et al [16]의 보고에 따르면 고온에서는 육 방정계(hexagonal) 구조로 준안정한 상태지만 저온에서는 단 사정계(monoclinic) 구조로 안정한 상태를 유지하게 된다. 이 러한 상변화로 인해 육방정계 구조의 밀도는 $8.448 \mathrm{~g} / \mathrm{cm}^{3}$ 이 고, 단사정계 구조의 밀도는 $8.270 \mathrm{~g} / \mathrm{cm}^{3}$ 으로 약 $2.15 \%$ 의 부 피 팽창이 발생한다. 이 부피 팽창은 $\mathrm{Cu}_{6} \mathrm{Sn}_{5}$ 에 내부 응력으로 작용하여 균열을 더 크게 발생시키는 것으로 생각된다. 그러 나 $\left(\mathrm{Cu}_{1-\mathrm{x}} \mathrm{Ni}_{\mathrm{x}}\right)_{6} \mathrm{Sn}_{5}$ 상은 $\mathrm{Ni}$ 이 들어가면서 결정구조의 변화가 발생하지 않고 육방정계 구조를 유지하기 때문에 $\mathrm{Cu}_{6} \mathrm{Sn}_{5}$ 보 다 균열의 길이가 짧고 파괴인성이 큰 것으로 판단된다. 문헌 을 살펴보면 본 실험과 동일하게 적정량의 $\mathrm{Ni}$ 이 첨가되었을 때 균열의 길이가 짧아지지만, $\mathrm{Ni}$ 함량이 일정량 이상 증가하 면 균열의 길이가 증가한다고 서술하고 있다 [16]. 이는 일정 량의 $\mathrm{Ni}$ 이 들어감으로써 $\mathrm{Cu}_{6} \mathrm{Sn}_{5} \mathrm{IMC}$ 내부에 적절한 응력장 을 발생시키고 균열의 전파를 막아주는 역할을 하는 것으로 예상할 수 있다. 그러나 $\mathrm{Ni}$ 의 함량이 증가하면 이러한 균열전 파를 차단하는 메커니즘이 작동하지 않는 것으로 판단된다.

\section{4. 결 론}

$\mathrm{Ni}$ 의 두께와 열처리 시간에 변화를 주어 솔더와 기판 사이 에 생성되는 IMC의 기계적 특성 변화에 대하여 고찰하였다. 그 결과 $\mathrm{Ni}$ 의 두께가 두꺼울수록 $\mathrm{IMC}$ 의 성장길이가 증가하 였으며, 성장속도 또한 증가하였다. 또한, 열처리 시간이 길 어짐에 따라 $\mathrm{IMC}$ 의 길이가 길어지며 성장속도도 빨라졌다. 나노압입시험 결과 $\mathrm{Ni}$ 의 두께가 두꺼울수록 $\mathrm{IMC}$ 내에 $\mathrm{Ni}$ 의 함량이 많아지므로 탄성계수와 경도값의 저하를 관찰할 수 있었다. 열처리 시간에 따라서는 비슷한 결과 값을 얻었지만 열처리 시간이 길어질수록 $\mathrm{IMC}$ 내부에 $\mathrm{Ni}$ 편석이 발생하고
그에 따라 탄성계수와 경도값의 편차가 커지는 것을 관찰하 였다. 또한, 형성된 IMC들은 변형 속도에 민감하게 반응하였 는데, 특히 $\left(\mathrm{Cu}_{1-\mathrm{x}} \mathrm{Ni}_{\mathrm{x}}\right)_{6} \mathrm{Sn}_{5}$ 의 경우 변형 속도 $1 \mathrm{~s}^{-1}$ 미만에서는 복수 돌출이 발생하고 $1 \mathrm{~s}^{-1}$ 이상에서는 사라지며 이는 전위의 움직임과 밀접한 관계가 있는 것으로 판단된다. 파괴인성은 $\mathrm{Ni}$ 의 두께가 두꺼울수록 작아지지만 적당량의 $\mathrm{Ni}$ 은 $\mathrm{Cu}_{6} \mathrm{Sn}_{5}$ 상에 비해 큰 값을 가지는 것으로 관찰되었다.

$\mathrm{Cu}-\mathrm{Ni}-\mathrm{Sn}$ 합금계에서 형성되는 IMC의 경우 $\mathrm{Ni}$ 의 두께가 두꺼워질수록 $\mathrm{IMC}$ 가 길어져 패키지의 신뢰성이 감소될 수 있겠으나, 적정량의 $\mathrm{Ni}$ 은 $\mathrm{Cu}-\mathrm{Sn}$ 합금계에서 형성되는 $\mathrm{IMC}$ 에 비해 형성되는 정도가 작고 상대적으로 큰 파괴인성을 가 지므로 $\mathrm{Ni}$ 를 이용한 표면처리는 패키지의 신뢰성을 향상시 킬 것으로 판단된다. 이 때 $\mathrm{Ni}$ 의 두께는 기계적 물성값이 크 게 떨어지지 않는 $2 \mu \mathrm{m}$ 이하가 적당하며 열처리 시간은 IMC 길이가 짧고 IMC 내부로 $\mathrm{Ni}$ 편석이 발생하지 않게 짧게 해주 는 것이 좋을 것으로 판단된다.

\section{감사의 글}

This research was co-supported by 1) the National Research Foundation of Korea (NRF) grant funded by the Korea government (MSIP) (No. 2015R1A2A2A01002795); 2) the Civil \& Military Technology Cooperation Program, through the National Research Foundation of Korea (NRF), funded by the Ministry of Science, ICT \& Future Planning (No. 2013M3C1A9055407).

\section{REFERNECES}

1. S. S. Ha, S. O Ha, J. W. Yoon, J. W. Kim, M. K. Ko, D. G. Kim, S. J. Kim, S. J. Kim, T. H. Hong, and S. B. Jung, Met. Mater. Int. 15, 655 (2009).

2. S. H. Kim, H. K. Shin, C. M. Park, D. U. Kim, P. R. Cha, U. H. Lee, and H. J. Lee, Korean J. Met. Mater. 53, 495 (2015).

3. M. H. Heo, N. Kang, S. Park, J. K. Kim, and W. S. Hong, Korean J. Met. Mater. 54, 908 (2016).

4. M. H. Jeong, J. M. Kim, S. H. Yoo, C. W. Lee, and Y. B. Park, J. Microelectron. Packag. Soc. 17, 81 (2010).

5. Y.C. Chan, Alex C.K. So, J.K.L. Lai, Mater. Sci. Eng. B. 55, 5 (1998).

6. J. W. Yoon, Y. H. Lee, D. G. Kim, H. B. Kang, S. J. Suh, C. W. Yang, C. B. Lee, J. M. Jung, C. S. Yoo, and S. B. Jung, J. Alloy. Compd. 381, 151 (2004).

7. J. W. Yoon, C. B. Lee, D. U. Kim, and S. B. Jung, Met. 
Mater. Int. 9, 193 (2003).

8. J. A. Lin, C. K. Lin, C. M. Liu, Y. S. Huang, C. Chen, D. T. Chu, and K. N. Tu, Crystals. 6, 12 (2016).

9. R. F. Pinzzotto and E. G. Jacobs, Proc. Reliability Physics Symposium, p.209, IEEE, Atlanta, GA, USA (1993).

10. M. Abbasi, A. Karimi Taheri, and M. T. Salehi, J. Alloys. Compd. 319, 233 (2001).

11. W. K. Choi and H. M. Lee, J. Electron. Mater. 28, 1251 (1999).

12. H. Rhee, J. P. Lucas, and K. N. Subramanian, J. Mater.
Sci - Mater. El. 13, 477 (2002).

13. H. Jun, Y. Kim, S. J. Lee, N. Kang, K. Kim, M. Kim, S. H. Kim, and D. Lee, Mater. Sci. Eng. A 612, 192 (2014).

14. D. Hull and D. J. Bacon, Introduction to dislocations, Butterworth-Heinemann, Amsterdam (2011).

15. H. Jun, Master of Science Thesis "Mechanical Properties of Sn-based Intermetallic compounds by Nanoindentation”, Pusan National University (2013).

16. K. Nogita, C. M. Gourlay, and T. Nishimura, JOM 61, 45 (2009). 